\title{
O Luto de Pais: Considerações Sobre a Perda de um Filho Criança
}

\author{
Cristine Gabrielle da Costa dos Reis ${ }^{1}$ \\ ${ }^{1}$ Universidade Federal de Santa Catarina, SC, Brasil. \\ Luísa da Rosa Olesiak ${ }^{2}$ \\ ${ }^{2}$ Universidade Federal de Santa Maria, RS, Brasil.
}

\author{
Mikaela Aline Bade München² \\ ${ }^{2}$ Universidade Federal de Santa Maria, RS, Brasil. \\ Alberto Manuel Quintana² \\ ${ }^{2}$ Universidade Federal de Santa Maria, RS, Brasil.
}

\author{
Camila Peixoto Farias ${ }^{3}$ \\ ${ }^{3}$ Universidade Federal de Pelotas, RS, Brasil.
}

\begin{abstract}
Resumo: A morte fora de lugar, a perda dos projetos futuros, das idealizações depositadas no filho e o lugar insubstituível que ele ocupa no imaginário dos pais dificultam o processo de elaboração do luto. Neste trabalho, buscou-se compreender como os pais vivenciam a perda de um filho ainda criança e discutir aspectos característicos desses casos. Foi realizada uma pesquisa qualitativa, em que se entrevistou 11 pais que perderam os filhos crianças, cujas mortes ocorreram em um intervalo que varia entre quatro meses e um ano e quatro meses em relação à entrevista. As entrevistas foram semiestruturadas com eixos norteadores que direcionaram os temas a serem abordados, e os dados foram trabalhados por meio da análise temática, revelando os núcleos de sentido da comunicação. Entre os principais elementos constituintes das narrativas, destacam-se: a dor incomparável, culpa, as experiências diferentes entre pais e mães, os outros filhos, o sentimento de perda de uma parte de si, a perda do objeto narcísico e a vivência do luto diante do funcionamento social contemporâneo. O estudo demonstrou a importância de considerar a singularidade do luto parental e não o confundir com a melancolia. Esses aspectos precisam ser reconhecidos, junto às diferenças que marcam as experiências distintas entre pai e mãe, o narcisismo dos pais e o contexto contemporâneo, a fim de auxiliar na construção de intervenções adequadas nesses casos. Sublinha-se a importância da fala na organização de uma narrativa que permita a construção de um sentido para a perda e a elaboração do luto.
\end{abstract}

Palavras-chave: Morte, Luto, Relações Pais-Criança, Narcisismo, Contemporaneidade.

\section{Parents' Grief: Thoughts on the Loss of a Child}

\begin{abstract}
The sudden death; the interruption of future projects, of the idealizations set upon a child; and its irreplaceable role within parents' imagination hamper the grief resolution process due to the loss of a child. Thus, this study aimed to understand how parents experience the loss of a child, discussing particular aspects related to this situation. Through a qualitative approach, semi-structured interviews guided by thematic axes were conducted with 11 parents who had lost their children between four months and one year and four months before the interview. Collected data underwent thematic analysis, revealing the communication cores. Incomparable pain, guilt, different experiences between fathers and mothers, other children, the feeling of losing a part of themselves, the loss of a narcissistic object, and the experience of grief towards the contemporary social functioning were the main elements present in parents' narratives. This study demonstrates the importance of considering the singularity of the parental grief without misinterpreting it as melancholy. To help developing appropriate interventions aimed at these cases, one must recognize the aforementioned aspects, as well as the differences
\end{abstract}


marking paternal and maternal experiences, parents' narcissism, and the contemporary context. The findings also point to the relevance of speech in organizing a narrative that enables the construction of a meaning for the loss and grief resolution.

Keywords: Death and Dying, Grief, Parent-Child Relations, Narcissism, Contemporaneity.

\title{
El Duelo de los Padres: Consideraciones Sobre la Pérdida de un Hijo Todavía Niño
}

\begin{abstract}
Resumen: La muerte fuera de lugar, la pérdida de proyectos futuros, de idealizaciones para el hijo y el lugar insustituible que este ocupa en lo imaginario de los padres hace que el proceso del duelo sea difícil. En este trabajo, se pretendió comprender cómo los padres vivencian la pérdida de un hijo aún niño y discutir los aspectos característicos de este caso. Para tanto, se realizó una investigación cualitativa, en que se entrevistaron 11 padres que perdieron hijos aún niños, cuyas muertes ocurrieron entre los cuatro meses y un año y cuatro meses antes de la entrevista. Las entrevistas semiestructuradas incluían ejes que direccionaron hacia temas predefinidos, y para el análisis de los datos se aplicó el análisis temático revelando los núcleos de sentido de la comunicación. Entre los principales elementos constituyentes de las narrativas se destacan: el dolor incomparable, la culpa, las experiencias diferentes entre el padre y la madre, los otros hijos, el sentimiento de perder una parte de sí, la pérdida del objeto narcisista y la vivencia del duelo por el funcionamiento social contemporáneo. El estudio demostró la importancia de considerar la singularidad del duelo parental y no confundirlo con la melancolía. Es necesario reconocer estos aspectos junto con las diferencias que marcan las experiencias distintas entre el padre y la madre, el narcisismo de los padres y el contexto contemporáneo, con la finalidad de contribuir con intervenciones adecuadas a esos casos. Se destaca la importancia del habla en la organización de una narrativa que permita la construcción de un significado para la pérdida y la elaboración del duelo.
\end{abstract}

Palabras clave: Muerte, Duelo, Relaciones Padres-Niños, Narcisismo, Contemporaneidad.

\section{Introdução}

No Brasil, a mortalidade infantil tem apresentado declínio ao longo dos anos. Em 2015, a taxa de mortalidade de crianças com menos de cinco anos de idade foi de 17,0 óbitos a cada mil crianças nascidas vivas. Resultado diferente do que era registrado em 1990, quando esse índice alcançava 52,5 óbitos a cada mil nascidos vivos (França et al., 2017). Mesmo que os índices tenham diminuído, as mortes de crianças ainda ocorrem e acarretam intensa dor aos pais (Freitas \& Michel, 2014; Lemos \& Cunha, 2015). Dados do panorama geral expõem que, em 2015, no Brasil, das dez principais causas de morte de crianças menores de cinco anos, nove estavam relacionadas a problemas de saúde, tais como: prematuridade, anomalias congênitas, asfixia e trauma do nascimento, septicemia (e outras infecções neonatais), infecção do trato respiratório inferior, desordens neonatais, doenças diarreicas, meningite e desnutrição (França et al., 2017).
O adoecimento, por sua vez, provoca um rearranjo na vida da criança, bem como no cotidiano familiar, especialmente quando se trata de uma doença grave (Menezes, Passareli, Drude, Santos, \& Valle, 2007). As mudanças que se estabelecem atingem tanto a reorganização de tarefas da rotina quanto os vínculos afetivos entre os membros da família (Quintana, Wottrich, Camargo, Cherer, \& Ries, 2011). Frente ao desconhecido e à ameaça de perda iminente, os familiares acompanham situações difíceis e dolorosas que envolvem procedimentos, maratonas de exames, consultas, tratamentos e internações recorrentes, o que compromete o bem-estar físico e emocional do conjunto familiar (Menezes et al., 2007).

Quando o adoecimento culmina na morte de um filho, a dor atinge os pais de forma particular, devido a essa morte se configurar como um acontecimento absurdo, uma inversão da ordem natural esperada, bem como pelo significado que esse filho tem para os 
progenitores. Com a perda do filho, perdem-se também os sonhos, as idealizações, os investimentos afetivos, as expectativas e os projetos que os pais tinham depositado na criança (Bittencourt, Quintana, \& Campos Velho, 2011; Menezes et al., 2007). Sob a perspectiva narcísica, o filho ocupa o centro da relação familiar, sendo responsável por realizar os sonhos dos pais. Assim, esse filho não pode - no imaginário dos pais - ser atingido por doenças, morte, renúncia do prazer e restrições à vontade própria. $\mathrm{O}$ narcisismo é o processo de constituição do eu: o ideal de ego imagem idealizada do eu - é construído pelo investimento que os pais projetam no filho, fazendo ressurgir seu narcisismo onipotente, do qual precisaram abdicar antes do nascimento da criança por conta da realidade. Assim, o que ele projeta como sendo seu ideal é o substituto do narcisismo perdido na infância, na qual ele foi seu próprio ideal (Freud, 1914/2006).

Cada sujeito que nasce recebe para si e para sua vida inteira uma gama de expectativas conscientes e inconscientes que são internalizadas. Esse mecanismo funciona como um "contrato narcísico implícito", que vincula cada geração à geração anterior. Além disso, tal mecanismo de expectativas garante um lugar que só existe pelo fato de cada membro investir narcisicamente no recém-nascido, um lugar que lhes confere o sentido de pertença e continuidade do grupo (Monti, 2008).

Nesse sentido, a morte de um filho faz emergir um desequilíbrio no núcleo da família, tendo em vista que os filhos, muitas vezes, desempenham funções que dão equilíbrio à dinâmica familiar (Luna, 2014). Com a morte, os pais têm que lidar com a ruptura do vínculo e elaborar um sentido para a perda (Bogensperger \& Lueger-Schuster, 2014), e na vivência da ausência, é essencial que reestruturem uma nova realidade sem o filho. Esse processo demanda a desconstrução de muitas expectativas vinculadas ao crescimento e ao processo desenvolvimental da criança, o que se configura como uma difícil tarefa perpassada por desafios e sofrimentos, além da possibilidade de os pais se sentirem debilitados em face da dor psíquica. Ainda, há a necessidade de arcar com a realidade, no que concerne aos afazeres, aos vínculos com a família e com os demais filhos, demandando sobreviver às angústias da perda. Perante essas repercussões, a possibilidade de viver a experiência do luto pode ser prejudicada, o que ocasiona dificuldades de lidar com os sentimentos e de expressá-los (Andrade, Mishima-Gomes, \& Barbieri, 2017).
Com o advento da morte, inicia-se o processo de luto, que corresponde a um trabalho de nível subjetivo. Ele representa uma resposta normal a uma perda, não sendo simplesmente um conjunto de sintomas que se desencadeiam, mas um processo que envolve uma sucessão de quadros clínicos que se mesclam e se substituem (Parkes, 1998), o que o caracteriza como dinâmico, flutuante e variável em natureza, intensidade e duração (Franqueira, Magalhães, \& Féres-Carneiro, 2015). Para Freud (1917/2006), o processo de elaboração psíquica se dá em decorrência da perda do objeto, gerando desinteresse pelo mundo externo e desequilíbrio dos investimentos libidinais. Diante da perda, há um intenso investimento libidinal no eu, e o sujeito deixa de investir nos objetos externos que não remetem àquele perdido: esse movimento é temporário, mas de fundamental importância para o processamento da perda (Freud, 1917/2006). Assim, com a perda do objeto, o vínculo precisa ser desfeito para que haja novos investimentos amorosos, ou seja, a elaboração do luto exige um trabalho psíquico do eu a fim de retirar o investimento no objeto perdido. Cada ligação com o objeto vai sendo investida, enquanto ocorre o desligamento com cada uma delas, de forma gradual, até que o processo avance e seja elaborado (Garcia-Roza, 2011).

Ainda que o luto seja considerado um processo singular, ele também depende de outros fatores, tais como: a forma que a perda é sentida, o quanto se está preparado para isso, como se deu a morte, os recursos psíquicos de quem sofre, a história pessoal, bem como as relações de apoio disponíveis e o vínculo com a pessoa que se perdeu (Viorst, 2005). Esses últimos elementos revelam as facetas relacionais e sociais envolvidas no processo de luto, que se somam e se inter-relacionam com o caráter singular e subjetivo intrínseco à perda.

As relações de apoio configuradas perante a demanda do enlutamento são de fundamental importância (Luna, 2014), pois têm o potencial de fomentar a capacidade de resiliência do sujeito enlutado (Almeida, 2017). Na vivência da perda, os vínculos de apoio desempenhamumaimportantefunção, inclusive na prevenção de complicações do luto. A importância desses vínculos, tais como amigos, familiares, comunidade etc., é tanta que sua falta pode levar o sujeito enlutado ao isolamento (Franqueira et al., 2015). Assim, um processo que funciona a nível subjetivo e que exige um trabalho psíquico considerável é também um 
processo relacional, em que o outro exerce uma função de extrema importância, tanto para a construção de um sentido referente à morte quanto para o fornecimento de apoio e amparo.

A elaboração do processo de luto exige que os pais encontrem momentos e espaços para ressignificarem tal ruptura psíquica, sendo importante que se respeite o processo de cada um, uma vez que essa tarefa exige a mobilização de recursos subjetivos que permitem o reencontro com formas de continuar a viver diante da perda do ente querido (Menezes et al., 2007). Contudo, os movimentos contemporâneos de intolerância ao sofrimento restringem os espaços para elaboração da perda. Atualmente, não há lugar para a falta e a incompletude (Campos, 2013), pois se valoriza cada vez mais a obtenção do prazer imediato e pouco se admitem perdas e frustrações (Santos, Oliveira, \& Jesus, 2015).

Essa lógica pode ser pensada a partir do avanço da medicina e do controle das epidemias, da morte e de males que provocam o sofrimento do ser humano. Nesse contexto, lançou-se um novo olhar para a saúde, para a morte e para o sofrimento: a felicidade e a saúde são postas como bens supremos, ao passo que o sofrimento é direcionado à esfera patológica. Isso lança o questionamento de qual a relação do homem com seu sofrimento, com a morte e com o corpo. Uma vez que os fenômenos sociais, emocionais e comportamentais passam a ser inscritos no binômio normal-patológico, essa relação é, muitas vezes, mediada pela medicalização, a qual tem por função anestesiar as dores e o sofrimento (Furtado, 2014). Esses fatores, por sua vez, promovem crescentes entraves à elaboração da perda e contribuem para a complexidade da vivência do processo de luto.

Tendo em vista os aspectos explorados em relação aos dados epidemiológicos sobre a mortalidade infantil, à importância dos filhos para o narcisismo dos pais e ao comportamento social diante da morte, da dor e do sofrimento, evidencia-se a potencial contribuição da presente investigação para o conhecimento sobre o tema do luto parental, uma vez que busca incluir a vivência de ambos os pais na perda dos filhos, tendo como background os movimentos contemporâneos. Com isso, é possível que a rede próxima de apoio e especialmente - os profissionais tenham subsídios teóricos para agir perante essa vivência, o que se desdobra em benefícios para os próprios enlutados. Para tanto, o presente artigo objetivou compreender como os pais vivenciam a perda de um filho ainda criança e discutir aspectos característicos desses casos.

\section{Método}

\section{Desenho do estudo}

Trata-se de uma pesquisa qualitativa, descritiva e exploratória desenvolvida com pais cujos filhos faleceram em decorrência de alguma doença. A pesquisa qualitativa busca explorar questões que envolvem os indivíduos e que, posteriormente, podem ser representadas pela capacidade interpretativa do pesquisador, capturando sentidos e significados dos fenômenos (Turato, 2013). A pesquisa exploratória, por sua vez, busca maior proximidade com o problema, visando torná-lo mais explicativo. Já o método descritivo foi selecionado por ter como aspecto central a descrição das características de determinado fenômeno ou população (Gil, 2002).

\section{Participantes da pesquisa}

Participaram da presente pesquisa pais que perderam um filho ainda criança, ou seja, com até 12 anos de idade incompletos, segundo a Lei no 8.069 (1990), que discorre sobre o Estatuto da Criança e do Adolescente (ECA). Foram incluídos pais que perderam seus filhos, por motivo de doença, quando eram ainda crianças e cujos óbitos tivessem ocorrido há mais de um mês e há menos de um ano em relação à coleta de dados. A definição desse intervalo se deve ao fato de o primeiro ano em relação à morte conservar características similares no que tange à vivência do processo de luto. Outro critério de seleção dos participantes foi que esses pais deveriam residir na cidade de Santa Maria, Rio Grande do Sul.

Os dados referentes à causa da morte, ao tempo em relação ao falecimento, aos nomes das crianças e dos pais e seus endereços foram consultados nas declarações de óbito disponíveis no Sistema de Informação de Mortalidade (SIM), junto a um servidor da Vigilância Epidemiológica da cidade, que foi responsável pelo acesso ao sistema. No sistema, não havia registro de nenhuma criança (dentro da idade, tempo e local estipulados para este estudo) que tivesse morrido por outra causa que não por motivos de saúde, fato que trouxe ao estudo a particularidade de trabalhar com o luto relativo à morte por doença.

No total, foram realizadas 11 entrevistas, em virtude de uma saturação dos dados, ou seja: depois que as informações coletadas se repetiram a partir de determinado número de participantes, 
novas entrevistas passaram a não ter acréscimos significativos para o alcance e a discussão dos objetivos propostos no estudo (Turato, 2013). Da totalidade das entrevistas analisadas, cinco foram realizadas com ambos os pais e seis apenas com as mães, por motivos variados, tais como: o pai não querer falar; acreditar que esse assunto deveria ser tratado com a mãe; estar fisicamente longe; ou pela mãe não ter mais o contato do pai e não haver outra maneira de encontrá-lo. A fim de proteger a identidade dos participantes, o nome dos pais foi trocado por $\mathrm{M}$, quando for mãe, e P, quando for pai, seguido de um número referente à entrevista, assim como os nomes que figuram nos depoimentos são fictícios.

Os participantes são apresentados com as informações referentes ao número de identificação, idade do(a) filho(a), causa da morte e tempo aproximado transcorrido desde o óbito: M1, 7 dias, infecção própria do período perinatal, 4 meses; M2, 11 dias, complicações cardíacas, 1 ano; M3 e P3, 5 dias, infecção própria do período perinatal, 1 ano; M4, 2 anos, malformação não especificada do coração, 6 meses; M5, 0 dia, feto/recém-nascido afetados por doenças infecciosas e parasitárias da mãe, 6 meses; M6 e P6, 9 anos, neoplasia maligna do encéfalo, não especificado, 1 ano; M7, 8 anos, cardiomiopatia dilatada, 9 meses; M8 e P8, 12 anos, morte sem assistência, 1 ano; M9, 0 dia, recém-nascido com peso muito baixo, 6 meses; M10 e P10, 4 dias, síndrome da angústia respiratória do recém-nascido, 7 meses; M11 e P11, 1 ano, hidrocefalia congênita não especificada, 7 meses.

\section{Coleta de dados}

O contato com os participantes se deu, na maioria das vezes, presencialmente, uma vez que foi fornecido à pesquisadora apenas os endereços dos pais. Alguns endereços não foram encontrados, principalmente por estarem incompletos ou incorretos. Muitos pais haviam mudado de residência, motivo pelo qual alguns participantes foram contatados via telefone (quando os vizinhos concediam o número) ou por meio de redes sociais virtuais, como WhatsApp e Facebook.

A coleta de dados foi realizada por meio de entrevistas semiestruturadas com eixos norteadores, uma vez que essa configuração confere maior mobilidade e flexibilidade, permitindo que o entrevistado discorra livremente, sem estar rigidamente preso às perguntas. Essa modalidade de pesquisa propõe a construção de um roteiro que serve como guia, composto pelos eixos norteadores (Minayo, 2014). Tendo isso em vista, a presente pesquisa contou com os seguintes eixos: o recebimento da notícia do adoecimento; o processo de tratamento e/ ou hospitalização; os sentimentos diante da perda iminente; a rede de suporte com a qual contavam; os sentimentos que emergiram perante a morte do(a) filho(a); a vivência da ausência do(a) filho(a). A pesquisa foi aprovada pelo Comitê de Ética em Pesquisa sob o número 52750016.6.0000.5346 e cumpriu todas as exigências éticas durante sua execução.

\section{Análise dos dados}

Primeiramente, foram realizadas as transcrições das entrevistas, a partir das quais procedeu-se a análise dos dados por meio da análise temática, que, segundo Minayo (2014), consiste em revelar os núcleos de sentido presentes na comunicação, cuja frequência de aparição pode ser significativa para o objetivo analítico. Essa análise consiste nas etapas: a) pré-análise; b) exploração do material; e c) tratamento dos resultados obtidos e interpretação.

As entrevistas foram lidas e relidas pela pesquisadora e outras três pessoas do grupo de pesquisa que auxiliaram no trabalho, a fim de discutir os assuntos suscitados. Inicialmente, cada entrevista foi lida e relida individualmente e os núcleos de sentido foram destacados conforme sua repetição nas narrativas e/ou importância para compreensão do fenômeno. Esses pontos foram posteriormente discutidos no grupo de pesquisa, constituído por quatro pesquisadoras. Após, as discussões foram ampliadas para serem conferidas por outros dois pesquisadores experientes na área. Nesse momento, os pesquisadores discutiram os aspectos relevantes e a consistência dos núcleos de sentido para a constituição desses elementos em categorias. Com isso, as categorias foram constituídas metodologicamente. Tal procedimento consiste em destacar assuntos que merecem discussão em grandes tópicos, podendo ser por critério de repetição ou de relevância (Turato, 2013).

\section{Resultados e discussão}

A morte de um filho representa um acontecimento incoerente na vida dos pais. Ao encontro de muitos achados da presente pesquisa, um estudo de 
Freitas e Michel (2014), desenvolvido com mães enlutadas, revelou os principais elementos constituintes de suas narrativas: a dor, a perda de um modo de existir e da vivência da espiritualidade, a culpa, a perda do sentido da vida, a fragmentação dos laços afetivos e a perpetuação da memória do filho (Freitas \& Michel, 2014). Esses resultados evidenciam a intensidade dos sentimentos que perpassam a vivência do luto de um filho. Em comum com os resultados do estudo citado, sublinham-se alguns elementos que também serão discutidos neste artigo: a dor, a culpa, o sentimento de perda de uma parte de si e a manutenção da memória do filho. Além disso, serão abordados os aspectos da elaboração do luto, as diferentes vivências que os pais e as mães têm, a dificuldade de processamento quando o objeto perdido é um filho, as implicações narcísicas, bem como os entraves provocados pelo funcionamento social contemporâneo.

Com intuito de destacar as particularidades do luto quando a vítima é um filho criança, serão apresentadas as categorias que costuram alguns resultados deste estudo. São elas: "Perda de um filho: uma dor sem comparação", "Mãe é mãe, pai é pai: as diferentes vivências dos pais", "Um ferimento narcísico" e "O luto impedido: vivências do sofrimento na contemporaneidade”.

\section{Perda de um filho: Uma dor sem comparação}

As narrativas referentes à morte dos filhos, relatadas no presente artigo, são permeadas por sentimentos de choque e incompreensão, o que pode estar relacionado ao fato de que, atualmente, no imaginário popular, criança e risco de morte estejam dissociados (Monti, 2008). Acrescenta-se a isso que a morte de uma criança representa uma inversão da ordem cronológica, o que provoca um forte impacto entre os membros da família, uma vez que os filhos representam seu foco emocional, nos quais são depositados expectativas e sonhos (Menezes et al., 2007). Há um sentimento de choque que se refere à morte do filho, o que faz com que a perda se torne demasiadamente dolorosa e incompreensível, como a fala de M2 exemplifica ao comparar a perda do pai à da filha:

Ah foi pior, né. Eu digo o pai, pior que eu sofra por ele, vivi 30 e poucos anos com meu pai e a Mariana vivi 11 dias e a dor é bem maior. É que o pai já quando nasce a gente vai crescendo e já vai sabendo que um dia a gente vai perder, né. Que isso vai acontecer. Agora filho não. E aí, tu perde um filho (M2).

A morte do filho, além de evidenciar a fragilidade humana, é uma morte fora de lugar, pois a morte do pai é esperada em algum momento da vida, mas não a morte do filho. Isso rompe a ilusão de que existe alguma previsibilidade e controle sobre a morte, como se ela tivesse um momento certo para acontecer. A literatura também traz apontamentos que indicam a singularidade do luto diante da morte de um filho, como Roitman, Armus e Szwarc (2002), que situam essa morte como uma perda impensável e inominável, para a qual não há palavras que possam designar um lugar. Outro exemplo é o estudo de Consonni e Petean (2013) em relação às vivências de mulheres que interromperam a gestação por malformação fetal letal, ressaltando que as mães vivenciam um período de intenso sofrimento, permeado por lembranças, pensamentos, fantasias e questionamentos sobre a experiência vivida. Também estão presentes sentimentos de tristeza, dor, angústia, desespero, desânimo e inconformismo.

Na presente pesquisa, constatou-se, nos depoimentos dos pais, a concepção de que a dor da perda de um filho é algo intransponível e incomparável, tal como no estudo de Freitas e Michel (2014), que situou essa dor como um sentimento de tamanha intensidade que não é possível sequer nomeá-lo, deixando clara a singularidade da dor da perda de um filho, como se pode ver nas seguintes falas: “. . . Olha, a gente até tenta, mas não... é uma dor que tu nunca vai esquecer. [chora]. Acho que eu não tenho como em palavras te falar..." (M5)

Mas assim, realmente, só quem passa por isso que sabe a dor de perder alguém. Eu já perdi pai, eu já perdi irmão, mas a dor de perder um filhoé... E sempre quando a gente fala sobre esse assunto... traz dor, traz muita saudade, é uma coisa assim que... a gente não esquece (M8).

Em ambas as falas, a ideia de se tratar de uma perda que nunca será esquecida é clara. Essa é uma concepção que aparece no discurso de quase todos os participantes. Nesse sentido, a perda não só não será esquecida, como não deve ser esquecida. As recordações e lembranças do filho perdido passam 
a representar a garantia de que ele nunca será abandonado (Andrade et al., 2017). Freud, em uma carta sobre a perda de sua filha, escreveu:

Ainda que saibamos que, logo após a perda, o estado de luto agudo se minimiza, também sabemos que seguiremos inconsoláveis e que jamais encontraremos um substituto. Não importa quando chegará o vazio, ou se chegará plena ou parcialmente; se permanecerá para sempre, ou se trará algo diferente. E, na realidade, é assim que deve ser. É a única maneira de perpetuar esse amor ao qual não queremos renunciar (Freud, 1929).

Tendo isso em vista, compreende-se que não há uma permissão para esquecer a perda, pois o esquecimento geraria culpa. O vazio e a falta de consolo descritos por Freud relacionam-se ao modo de perpetuar o amor pela filha perdida. Cremasco, Schinemann e Pimenta (2015), sob uma perspectiva psicanalítica, analisam mães que perderam filhos e explanam que a renúncia do sofrimento gera um grande sentimento de culpa, pois se concebe que toda mãe que realmente ama seu filho nunca mais será feliz sem ele. Os resultados do estudo de Consonni e Petean (2013) evidenciam que, ao falarem sobre os filhos e sobre as lembranças que têm deles, as mães do estudo assumem o compromisso de nunca esquecê-los, independentemente do tempo que passar.

O sentimento de culpa, ainda, pode surgir frente à vivência de um longo processo de adoecimento e internações recorrentes. $\mathrm{O}$ adoecimento prolongado, que envolve muito sofrimento, é frequentemente desgastante e perpassado por sentimentos ambivalentes, uma vez que pode haver o desejo de morte para alívio do sofrimento e, ao mesmo tempo, esse desejo pode provocar culpa (Kovács, 2003). Esses sentimentos ambivalentes podem ser visualizados no P11, cujo filho já nasceu com uma anomalia e, durante o tempo que esteve vivo, passou por muitos procedimentos cirúrgicos e internações recorrentes. A fala desse pai retrata uma situação sobre os momentos críticos da criança, pouco antes do falecimento: “. . . eu segui naquela mania: pede pra ir, pede pra voltar, pede pra ir, pede pra voltar... E na passada eu pedi que se fosse pro bem dele, que Nossa Senhora levasse. Eu não entrei no quarto. Levou mesmo" (P11).

Nessa lógica, Roitman et al. (2002) destacam que há uma ordem do superego que impede o desligamento com o objeto perdido. Os autores discorrem, com base em suas experiências clínicas, que alguns pais resistem, seja consciente ou inconscientemente, a diminuir seu sentimento de dor, uma vez que o sofrimento parece representar a prova de seu amor em relação aosfilhos. Isso ocorre em decorrência da necessidade de o(a) filho(a) existir, mesmo que seja porhábitose recordações, para quenão haja, assim, o risco de esquecê-lo (Andrade et al., 2017).

Essa é uma particularidade que pode ir ao encontro da difícil elaboração do luto nesses casos. O trabalho de luto, segundo Freud (1917/2006), consiste em hipercatexizar cada uma das lembranças cuja libido está ligada ao objeto e, posteriormente, retirar a libido das ligações do objeto perdido, realizando, pouco a pouco, o desligamento de cada uma delas. Quando o trabalho de luto é elaborado, o ego se torna outra vez livre e desinibido. Ou seja, em um primeiro momento, o objeto perdido ocupa um lugar central e, aos poucos, vai figurando em um espaço de plano de fundo (Franqueira et al., 2015). Assim, para que a elaboração do luto ocorra, o familiar precisa interiorizar o objeto perdido (Andrade et al., 2017).

Entende-se que há uma resistência em elaborar o luto por medo de que isso represente o esquecimento do filho. O sofrimento permanente seria, nessa concepção, a prova de amor dos pais. Dessa maneira, estabelece-se uma relação com a dor como expressão do amor: “. . . é como uma ferida que tá aberta, quando fala dói [chora]” (M8).

Freud (1917/2006), aborda o luto para explicar a melancolia, demonstrando que em ambos os casos estamos frente a manifestações semelhantes, ainda que distintas. Considera-se que, na problemática tratada neste artigo, essa comparação possa auxiliar em sentido inverso, ou seja, partindo da melancolia para chegar ao luto. Para isso, identificam-se dinâmicas que, tanto na melancolia quanto no luto, dificultam a retirada das ligações com o objeto amado: em ambos os casos, se está diante de expressões oriundas de uma perda. Excluindo a perturbação da autoestima, que estaria ausente no luto, em ambos os casos os traços encontrados são os mesmos: perda de interesse pelo mundo externo; desânimo profundo que leva a um desinteresse geral pela vida; inibição de qualquer atividade. O que vai diferenciar ambos os processos é que, tratando-se da melancolia, existe uma impossibilidade do desligamento da libido de cada uma das lembranças ligadas ao objeto perdido. Mas no luto 
em face da morte de um filho, não estaríamos frente à mesma dificuldade de desligamento? É interessante prestar atenção na explicação que Freud concede para a forte fixação no objeto que, no caso da melancolia, impediria o desvinculamento, dificultando o processo de luto. Ele considera que o motivo para isso está relacionado ao fato de que "a escolha objetal é efetuada numa base narcisista" (Freud, 1917/2006, p. 282). Contudo, essa situação também se apresenta perante a morte de um filho ainda criança, podendo ser tomada como um fator comum a ambos os processos. Na perda de filhos crianças, o investimento que os pais desenvolvem está alicerçado na revivescência do seu narcisismo onipotente, conferindo uma base narcísica para tal.

Nessa trajetória, além do movimento de investimento e desinvestimento, é preciso que o sujeito elabore as fantasias conscientes e inconscientes ativadas em decorrência da perda do objeto, em um redimensionamento das defesas e das fantasias do psiquismo, em busca do estabelecimento de um novo equilíbrio de forças (Campos, 2013). Como se pôde observar nas falas citadas nessa categoria, a dor, a impotência e a culpa são sentimentos recorrentes no processo de elaboração da perda, o que vai ao encontro de outros estudos (Freitas \& Michel, 2014; Lemos \& Cunha, 2015; Menezes et al., 2007).

O amor pelos filhos permanece mesmo após a morte, tal como o lugar parental. Há a ideia de que, independentemente da morte, os pais continuam sendo pais. Estudos como os de Bogensperger e Lueger-Schuster (2014) e Santos et al. (2015) expressaram a identificação de alguns pais com o papel parental mesmo após a morte dos filhos. O primeiro deles buscou aprofundar o olhar sobre a reconstrução de sentido em pais enlutados e evidenciou que muitos acreditam que sua identidade enquanto pais não se esvai com a morte do filho. Santos et al. (2015) apontam que um de seus achados se refere ao fato de que, quando questionados sobre quantos filhos os participantes tinham, todos incluíram o filho morto como membro da família. Em relação a isso, a fala da M10 explicita: "Eu lembro no dia das mães, uns quantos vinham 'ah, feliz dia das mães' e cruzavam por mim. Maaas! Eu também sou mãe". Tendo em vista as concepções culturais que envolvem a maternidade, ser mãe é, sobretudo, um modo de existir socialmente. Quando morre um filho, a mãe não adquire um novo lugar, pois não há denominação para uma mãe que sobrevive à perda do filho (Freitas \& Michel, 2014). Posteriormente, a mãe conta uma história de outra mulher que esteve hospitalizada junto a ela e, quando fala a respeito da perda dela, diz "graças a Deus ela tinha outros filhos". Quando questionados a respeito dessa expressão, os pais discorrem: "Ela tem que dar atenção pra aqueles dois, né. A gente não tem. Não tinha. Não tem." (P10). "Não vai tirar a dor dela. Não, de forma alguma, mas... que bom que ainda tem...” (M10).

Sublinha-se que o fato de ter outros filhos é um aspecto recorrente nas entrevistas. Os outros filhos aparecem como motivo para que os pais possam seguir em frente e tenham um porquê para isso, o que coincide com a pesquisa de Almeida (2017), além do fato de que a identidade, enquanto pai e mãe, dá-se em uma realidade concreta: "Então... quando tu tem outro filho, tu tem que buscar mais força ainda, né, pra ti te manter... porque tu tem que ter força pra ficar com o outro, o outro também precisa de ti" (M4); “... Então essa falta a gente sente muito. E a gente tenta olhar, assim, pra ele, graças a Deus tenho ele pra continuar lutando por ele, ensinando ele" (M8).

Dá, dá uma força. A gente não pode pensar... tem que pensar muito nele. A gente não tem vontade nem de tirar férias, sair, viajar, ir pra praia, passear... mas ao mesmo tempo a gente sabe que tem que voltar (P8).

Lidar com a perda de um filho se apresenta como uma vivência difícil, que pode perpassar diferentes manejos em relação à configuração familiar. Ter outros filhos transmite aos pais a ideia de que precisam continuar investindo no mundo externo e em suas relações. Além disso, como se observa na presente categoria, esquecer o filho que faleceu ou deixar de sofrer por ele seria uma forma de abandono que se somaria à culpa por não ter conseguido protegê-lo e não corresponder à imagem que a criança projetou nos pais de um ser onipotente que poderia defendê-la contra todo mal.

Coloca-se em evidência a recorrência que o sentimento de culpa e o sofrimento têm nas narrativas. A culpa é um sentimento que pode ser ativado em decorrência das fantasias conscientes e inconscientes despertadas após a perda do objeto. A morte do filho, além da intensa dor descrita pelos pais, os coloca diante de sua impotência perante a morte e da incapacidade de salvar seus filhos. Nesse sentido, 
em um movimento reparador da perda, os pais vinculam o sofrimento ao amor pelos filhos, assumindo o compromisso de nunca esquecê-los. Esse é um fator que colabora com a dificuldade de desligamento do objeto perdido. Dada a importância desses elementos para a compreensão e o desenvolvimento do processo de luto, na próxima categoria, tais sentimentos serão desdobrados também como aspectos que marcam a diferença nas vivências entre a mãe e o pai.

\section{"Mãe é mãe, pai é pai": As diferentes vivências dos pais}

Ambos os pais expressaram questões e sentimentos que envolvem a morte do(a) filho(a), mas a culpabilização aparece predominantemente no discurso das mães, o que coincide com a pesquisa de Freitas e Michel (2014). Culturalmente, cabe ao papel materno a responsabilidade de assegurar a coesão familiar, bem como a integridade dos filhos a nível físico e psíquico. No que concerne ao papel paterno, frequentemente, as exigências se referem às necessidades de ordem material, o que reflete, muitas vezes, em lacunas no aspecto afetivo, situação que pode causar dificuldade na demonstração de sentimentos em relação à perda e no resgate das memórias do filho falecido (Quintana et al., 2011). Na fala a seguir, é possível observar a repressão dos sentimentos quanto à morte do filho. No entanto, isso não parece ser sinônimo de não sentir a perda ou de não sofrer, mas, possivelmente, retrata um cenário cultural em que os homens devem ser mais fortes e sustentar a casa, seja financeira ou emocionalmente:

... Não tem... como é que eu vou te explicar, se os dois desmoronam em casa, termina com a casa, né. Então... eu já sou um pouco mais reprimido, sabe. ... Então assim, naquele momento, eu tive que ser o mais forte, sei lá, e os filhos em casa também... (P3).

As mães ainda são consideradas as principais responsáveis pelos cuidados dos filhos e representam uma figura protetora, onipotente e onisciente. Diante da relação de cuidado que se torna muito intensa, pode emergir uma confusão de percepções e sentimentos, uma vez que as ações das mães parecem ser responsáveis pela cura dos filhos. Assim, surge um sentimento de impotência e desamparo perante a situação de adoecimento e morte à medida que essas mães não conseguem salvar seus filhos (Freitas \& Michel, 2014; Quintana et al., 2011), como se não tivessem sido boas mães o suficiente:

Sabe, porque eu fico pensando assim 'ai porque eu não tive tanta fé', 'ai porque eu mereci isso'. É muito porquê. É muita condenação da minha parte. Porque daí eu fico pensando assim: se eu conseguisse segurar mais um pouco? Ele não teria ido pra UTI. O porquê de acontecer comigo, que eu fiz pra merecer isso... (M1).

Quando o filho nasce prematuro e, por conta disso, tem uma saúde mais frágil e desenvolve problemas de saúde, é comum que as mães se culpem por "não ter segurado mais", como diz a M1 e como pode ser visto no relato a seguir da M10. Para ela, pesa ainda o fato de associar sua melhora ao nascimento da filha, pois a gestação trazia limitações físicas consideráveis:

Eu lembro que ali me deu um desespero, daí eu "não, eu posso mais ainda". Porque eu pensava nela, então, naquele momento eu fiquei com aquilo ali, eu tinha que ter ido um pouco mais. A gente se culpa. Ainda mais saber que ela nasceu e eu melhorei. Tipo, ela me salvou. Ela tinha me salvado e eu não pude salvar ela (M10).

Na fala acima, ainda é possível visualizar uma sensação de fracasso ao não poder salvar a filha. Estudos como o de Lemos e Cunha (2015) apontam que, além do sentimento de culpa, as mulheres, muitas vezes, nutrem fantasias a respeito do fracasso e do funcionamento incorreto de seu corpo. O sentimento de culpa ainda pode ser observado quando, diante da morte, há $a$ sensação de seu amor e proteção terem falhado (Bittencourt et al., 2011). Mesmo que no discurso a seguir, do pai, apareça a demanda de um sentido para a perda, nas narrativas das mães, o sentimento de culpa é mais evidente, como é possível observar no diálogo entre os pais: "Conforme vai passando o tempo, começa a surgir alguns questionamentos na tua cabeça, aquela coisa 'por que com a gente? Por quê??" (P8); “Uma coisa de culpa, nê" (M8).

A concepção de que as mães sofrem mais a perda dos filhos que os pais está presente tanto na narrativa de algumas mães, como no discurso de alguns pais: "E também tem aquela coisa, por mais que a gente não queira, mãe é mãe, entende? Mãe é mãe. É quem 
carrega na barriga. Tem algo de Deus, da natureza que faz essa diferença” (P8); “Como diz 'é pai, é mãe' a gente sente como isso é diferente. Nela muito mais, né... mãe, mãe é mãe, pai é pai. Mas ela carregou, ela sentiu dor, o que eu pude eu tava com ela" (P10).

Retoma-se a discussão já desenvolvida acerca das diferenças culturalmente estabelecidas, uma vez que a análise da dinâmica conjugal de um casal (Morelli, Scorsolini-Comin, \& Santos, 2013) após a perda de um filho revelou que o processo de luto da mãe é mais comprometido. O pai do estudo atribui isso ao fato de "ser mãe". Como é possível visualizar nas falas acima, os aspectos biológicos da maternidade, tais como a gestação, o parto e a amamentação, conferem à mãe uma experiência única e exclusiva (Freitas \& Michel, 2014). Ao encontro dos achados da literatura, na fala de M3 está presente que o vínculo que a mãe estabelece com o filho tem início desde a gestação, o que geraria uma dor ainda maior:

... porque assim, mãe e pai, realmente, é muito legal, mas eu acho que quem sente mais é uma mãe. Porque tu carrega aquele nenê por nove meses. Tu passa sufoco, tu não dorme mais direito, né. Tua barriga cresce, tu não tem roupa pra usar. E levanta de madrugada, com fome, com dor, com cãibra ou e vice-versa e não consegue dormir por causa da barriga, né. Então eu acho que quem sente mais essa dor imensa é uma mãe (M3).

É possível marcar uma diferença no discurso entre os pais, uma vez que há a relação entre a maternidade e uma dor mais profunda. Somado aos depoimentos aqui analisados, acrescenta-se outro fato: o de alguns pais não quererem participar da presente pesquisa, ou delegarem a responsabilidade de falar sobre a perda do filho às mães. Sobretudo, é importante destacar que o casal vivencia a mesma perda, mas de maneiras diferenciadas, dadas as singularidades do processo de luto (Morelli et al., 2013).

Ao falar sobre a perda de um filho, fica evidente o caráter subjetivo implicado no processo de elaboração do luto. Esse é um fator que não pode estar descolado do contexto cultural no qual a perda acontece, pois ao considerar a presente categoria, os fatores culturais marcam diferenças nas vivências entre pais e mães. Nesse sentido, acredita-se que a dor mais intensa é vivida pelas mães, o que está presente nos discursos de ambos os pais, e deve ser considerada a partir dos fatores subjetivos de cada sujeito e dos elementos de uma cultura que valida a posição da mãe como principal responsável pelo amor e cuidado aos filhos. Além de todos os elementos abordados, evidencia-se o lugar psíquico que esses filhos ocupam para os pais, pois os aspectos inconscientes que envolvem a perda também influenciam, de maneira significativa, o modo como os pais elaboram o luto.

\section{Um ferimento narcísico}

Dados os aspectos já abordados sobre a singularidade do luto diante da perda de um filho, destacam-se também os fatores inconscientes, como o narcisismo dos pais, que influencia o modo como essa perda é sentida. Cabe destacar que o investimento dos pais nos filhos, nos quais é projetado o ideal de ego, faz com que se desenvolvam, em seus imaginários, uma fantasia onipotente de que os filhos não podem ser acometidos pelo sofrimento ou pela morte (Freud, 1914/2006). Assim, o amor dos pais e sua atitude afetuosa com seus filhos remete ao seu narcisismo renascido que sofre uma transformação em amor objetal, o que remete a um forte vínculo amoroso entre o sujeito e o objeto de base narcísica, que se trata de uma imagem ou ideal (Garcia-Roza, 2011).

Tendo isso em vista, o bebê se torna o suporte das projeções narcísicas dos pais. Ele existe, nesse sentido, para indenizá-los narcisicamente (Freud, 1914/2006) e, ainda, para garantir a continuidade das gerações e um sentimento de continuidade do grupo familiar (Monti, 2008). Nas entrevistas, é possível visualizar que, por vezes, cada filho aparece como objeto narcísico insubstituível: "Pode ter outros filhos, eu acho, mas... Aquela criança foi única, nê" (M4). "Tu sabe que tu teve... por 7 dias, mas teve. Era teu. Sabe... depois tu se deparar sem aquilo ali. É horrível . . . Não tem... Outro não vai substituir ele" (M1).

Ao encontro dessas narrativas, Cremasco et al. (2015) apontam que, no discurso das mães cujos filhos vieram a óbito, é comum aparecer que com a morte do filho há o sentimento de perda de uma parte de si, como se os filhos funcionassem como extensões delas. No estudo de Freitas e Michel (2014), desenvolvido com mães enlutadas, as narrativas destacam não só o fato de ter morrido a relação com seus filhos, mas também uma parte delas. Dessa maneira, a perda de um dos filhos é algo irreparável, mesmo havendo outros filhos (Freitas \& Michel, 2014). 
Essas observações coadunam os apontamentos de Freud (1914/2006) sobre a concepção narcísica dos filhos como parte do próprio corpo, uma extensão dos próprios pais. Em termos de elaboração de luto, o rompimento do vínculo entre o sujeito e o objeto de escolha narcísica propõe um desinvestimento gradual, prolongando a existência desse objeto perdido, uma vez que há, por parte do sujeito, dificuldade em abrir mão de sua posição libidinal, mesmo que esse objeto tenha sido perdido e haja algum substituto enquanto possibilidade (Garcia-Roza, 2011).

Nesse contexto, no presente estudo, evidencia-se que os filhos parecem ser a continuidade dos próprios pais, uma vez que sua morte representa um desconhecimento de si e um abalo na sua identidade. Pensar o narcisismo segundo sua relação de complementaridade (Campos, 2013) indica que o eu e o outro se complementam, ou seja, a morte do filho também significa a perda de parte complementar de si, o que deixa em evidência a falta. Na fala da M1, é possível perceber essa incapacidade de ser feliz e retomar a vida, pois parte de si está faltando, enquanto para o $\mathrm{P} 11$, a perda ocasiona uma ruptura $\mathrm{e}$ uma vida desconhecida:

Mudou assim porque... Não digo que eu nunca mais vou ser feliz, sabe, porque eu também não sei, mas por enquanto eu não sou a mesma. Eu sorrio, eu brinco, mas eu não tenho mais a felicidade que eu tinha até o dia em que aconteceu tudo isso (M1).

O que mais dói é a falta. Eu não sei se foi porque foi muito intenso, foi uma entrega nossa por completo, é... sem escolhas, sabe ... Praticamente nós deixamos de viver a nossa vida e vivemos a vida dele. Ou a vida que ele queria que a gente vivesse, melhor dizendo (P11).

Reitera-se que a relação entre pais e filhos é permeada por uma série de expectativas, uma vez que os pais projetam muito de si nos filhos e que eles representam extensões dos próprios pais. É nesse sentido que se pode compreender que quando ocorre a morte de um filho, ou seja, o rompimento definitivo dessa relação, as mães - como cita o estudo de Cremasco et al. (2015) - assumem um discurso de se sentirem sem uma parte de si, ou seja, de estarem incompletas. Os filhos são os objetos narcísicos que permitem aos pais continuarem suas idealizações, uma vez que ter um filho - que remeteria a um momento de revivescência e fortalecimento narcísico dos pais - transforma-se em uma ferida narcísica, o que, acredita-se, pode influenciar de modo a tornar o processo de luto dos pais particularmente doloroso. Dessa maneira, a morte de um filho pode ser demasiadamente penosa, pois junto ao filho, morrem também os sonhos e as expectativas que os pais tinham em relação a ele e tudo de si mesmos que ele representava (Santos et al., 2015). Em outras palavras, seu narcisismo infantil é novamente abalado pela realidade.

A fissura narcísica que se abre diz respeito à dificuldade dos pais de lidarem com a finitude daquilo que representava o mais alto grau de sua perfeição, ou seja, com o real da morte, o limite de sua onipotência frente a ela. Os filhos, enquanto objetos narcísicos e representantes dos sonhos e idealizações dos pais, ao morrerem, levam junto parte da própria identidade dos pais, o que exige um árduo trabalho psíquico que busque cicatrizar e atribuir sentido a esse ferimento narcísico. Tendo em vista a importância dos aspectos psíquicos e ao buscar compreender as forças exercidas por diferentes vértices, cabe reiterar que o luto também é atravessado pelos fatores sociais que serão explorados na categoria a seguir.

\section{O luto impedido: Vivências do sofrimento na contemporaneidade}

A morte, atualmente, tem ganhado outros contornos e tem sido colocada à distância: o homem contemporâneo mudou sua relação com a morte e, consequentemente, com o luto. Assim, a perda pode produzir uma solidão considerável (Santos et al., 2015), pois a falta da reflexão sobre a morte também pode gerar dificuldade de desenvolver recursos para lidar com as perdas e o luto.

O contexto em que se dá o processo de elaboração do luto é de fundamental importância, uma vez que este processo é também um trabalho relacional, em que a produção de sentido para a perda e a construção de uma narrativa que possa dar significado à experiência vivida passa pelo outro. Dessa maneira, compartilhamento social e relações de apoio contribuem para a vivência do luto (Luna, 2014).

Para tanto, o processo de luto exige tempo e espaço afetivo - para compartilhar - e psíquico - para elaborar. Todavia, segundo Campos (2013), a passagem da cultura moderna para a pós-moderna narcísica é marcada pela impossibilidade de reconhecimento da 
falta constitutiva de todos nós, cujo maior emblema é a morte. Kovács (2003), ao encontro desse viés, traz a concepção de morte interdita, que faz com que o processo de luto sofra interferência, uma vez que é preciso agir de forma discreta, como se a dor não existisse, a fim de não provocar situações de constrangimento.

Evidencia-se, na contemporaneidade, um movimento de barrar o sofrimento, imposição que parece prejudicar o trabalho do luto. Há algo da ordem do sofrimento que não pode ser sentido, e, menos ainda, expressado. Isso pode ser pensado em termos da dinâmica social contemporânea, em que se preza pelo "imperativo da felicidade", tornando intoleráveis as manifestações de dor (Furtado, 2014). A proibição da manifestação do sofrimento fica clara na fala da M1, quando o marido usa em seu discurso o filho como motivo para que a mãe não chore - pedindo que ela o deixe descansar - e, especialmente, que ele não tenha que sustentar isso, uma vez que segundo Kovács (2003) o sofrimento pode parecer contagioso e as expressões de emoções muito intensas costumam ser de difícil manejo: "Sim, porque ele pedia pra mim... ele dizia 'ai, deixa o guri descansar'. Eu dizia 'eu deixo ele descansar', aí eu acabava me irritando com aquilo ali, sabe" (M1).

Então eu foquei: eu não posso... meu psicológico tem que tá bom. Então tipo... eu ser muito fortona, de não querer sentir alguma coisa por medo de depois me atrapalhar. Então, às vezes, eu acho que eu me cobrava muito assim de: não, tem que ficar bem... Mas sozinha não adiantava, sozinha ninguém tava vendo, então... (M10).

O depoimento acima deixa evidente as cobranças da esfera social, pois a entrevistada se mostrava bem em frente aos outros, mas quando estava sozinha manifestava o que realmente sentia. Há uma exigência social de que a pessoa enlutada lide com a perda de maneira contida, manifeste força e controle, para que as pessoas não fiquem constrangidas (Kovács, 2003). Ademais, os próprios sujeitos em sofrimento adotam esse discurso de controle sobre suas expressões de dor. Quando M10 fala de “. . . ser muito fortona, de não querer sentir alguma coisa por medo de depois me atrapalhar ...", revela o funcionamento performático atual em que a lógica do ser reside no aparecer, ou seja, "aparecer para ser"; por outro lado, tudo que permanecer oculto, longe dos olhares do outro, corre o risco de não ser visto e, portanto, não existir (Furtado, 2014).
Nesse contexto, a regra social implícita envolve a neutralização dos ritos funerários, além da ocultação de tudo que diga respeito à morte, o que - reitera-se implica diretamente na forma que se vivencia o luto (Freitas, 2013), como é possível visualizar na fala da M2: "Meu tio disse assim: 'nem fica muito tempo pra enterrar, pra ti não ficar sofrendo, né. Vai ali rápido e sepulta ali e enterra pra não ficar sofrendo"'. Luna (2014), nas narrativas sobre as histórias de perdas, verificou que, na cultura ocidental, é possível visualizar a pouca importância dada à participação dos rituais de morte.

Tendo isso em vista, na fala de M7, observa-se uma associação feita pela mãe entre a vivência da dor e suas reações naturais - tal como o choro com a depressão: “ $A$ h, ser forte, pensar que se eu ficar chorando pelos cantos, ficar depressiva, é pior, vai ser o que, daí, uma pessoa depressiva, acho que a vida fica muito pior". É possível perceber que a dor e o sofrimento, antes compreendidos como vivências próprias da vida e, por isso, irremediáveis, são inscritos na esfera das patologias (Furtado, 2014). Nesse contexto, o luto, como expoente representativo da dor, passa a ser percebido como vivência patológica, e não mais como um processo que faz parte da vida (Freitas, 2013), o que pode levar o enlutado a ficar estagnado entre o peso de seu sofrimento e o interdito social (Kovács, 2003). Da patologização desses fenômenos, ainda decorrem os processos de tratamento e medicalização, que, por sua vez, desempenham a função de anestesiar a dor (Furtado, 2014). Sendo a dor anestesiada e, por isso, não sentida, ela também deixa de ser elaborada e significada, o que, reitera-se, dificulta a possibilidade de elaboração da perda e do processamento da dor.

Nesse processo, ao contrário do escamoteamento ou do anestesiamento da dor e da perda, os pais podem encontrar suportes que auxiliem na elaboração psíquica dessa perda e que forneçam apoio para o enfrentamento dela (Almeida, 2017), como a rede de apoio que, frequentemente, figura como fornecedora de recursos e continência, oferecendo segurança para que o sujeito sinta que pode sobreviver à perda ao entrar em contato com seus sentimentos e frustrações. Além do mais, na era digital, ressalta-se a procura por grupos na internet como um instrumento que auxilia na identificação com outros pais, nas trocas e no compartilhamento das vivências (Franqueira et al., 2015). Destarte, 
os enlutados devem ser encorajados a comunicar os próprios sentimentos, a fim de possibilitar que o indivíduo ressignifique a perda e elabore seus sentimentos (Andrade et al., 2017).

Cabe retomar que o luto é um processo composto por diferentes facetas, tais como a subjetiva, a cultural e a social, e que todas elas desempenham notável importância para seu processo de elaboração. Com efeito, as mudanças histórico-sociais da relação do sujeito com a morte acabam por rechaçá-lo do nosso convívio, o que se soma à era de um imperativo social da saúde e da felicidade que patologia as manifestações de dor ou sofrimento, as quais devem ser silenciadas. A lógica social contemporânea de silenciamento e anestesiamento do sofrimento vem de encontro às necessidades inerentes à elaboração do luto, como a escuta para verbalização de um discurso que dê contorno para a perda; a possibilidade de lidar com a própria dor e manejá-la de acordo com os recursos psíquicos disponíveis; e a disponibilidade dos vínculos afetivos que são capazes de oferecer apoio e amparo, auxiliando na construção de bordas para o sentimento de dor intensa. Assim, considera-se que esse movimento contemporâneo restringe as possibilidades do desenvolvimento de recursos para lidar com a perda, uma vez que, nesse contexto, ela deve ser escondida, levando à fragilização dos sujeitos enlutados.

\section{Considerações finais}

Um dos aportes deste trabalho é relativizar as manifestações do luto parental diante da perda de um(a) filho(a) ainda criança, procurando diferenciá-las de manifestações próprias à melancolia. Isso é fundamental para a construção de intervenções terapêuticas alinhadas com a singularidade desse processo de luto. Além disso, este artigo buscou evidenciar as diferenças entre as vivências da mãe e do pai frente ao impacto da morte do(a) filho(a), o que possibilitou inferir sobre a necessidade de se considerar tal diferença nos casos de um acompanhamento terapêutico, principalmente no que se refere aos aspectos narcísicos envolvidos. Tendo em vista o lugar que o(a) filho(a) falecido(a) ocupa na identidade de cada um dos pais, acredita-se que as intervenções terapêuticas possam ter como um de seus pilares o auxílio à elaboração da ferida narcísica causada por tal perda, contribuindo assim para a reconstrução do narcisismo.

A partir das particularidades das vivências de luto dos pais, exploradas neste artigo, e das proibições contemporâneas em relação ao sofrimento, destaca-se a importância de permitir que os pais sintam e expressem sua dor de acordo com seu tempo e capacidade singular. Tendo em vista que o luto permite uma reconstrução narrativa, é preciso que os pais encontrem espaços para contar e recontar suas dores, organizando uma história que os permita construir sentidos e elaborar sua perda. Deve haver um esforço, portanto, para que os círculos sociais e profissionais - envolvidos sejam capazes de suportar a escuta, de modo a não proibir suas expressões nem menosprezá-las. Ainda, que o luto possa ser entendido como uma reação natural a uma perda importante e, por isso, dolorida, sendo a dor constitutiva da vivência desse momento.

Citam-se algumas limitações da pesquisa, tais como o fato de muitos pais não terem sido encontrados, seja por mudanças ou registros incompletos dos endereços no sistema. Outra limitação se refere a não ter sido possível criar um grupo mais homogêneo quanto à idade da criança, devido às dificuldades já referenciadas de encontrar os participantes e, assim, ter havido um número reduzido de possibilidades. No entanto, pôde-se verificar vivências semelhantes, tendo em vista os diversos fatores que influenciam o processo de luto, não sendo possível afirmar que a idade da criança, isoladamente, seja uma variável que marque a diferença das vivências.

Apesar disso, reitera-se a contribuição do estudo para a produção de conhecimento sobre o tema do luto parental, uma vez que busca apresentar uma discussão que associa os elementos psíquicos aos sociais contemporâneos. Dessa forma, o estudo é capaz de oferecer subsídios teóricos para o manejo do luto nesses casos, tanto para os profissionais da saúde quanto para aqueles que são próximos aos pais enlutados. As contribuições científicas da pesquisa se desdobram em benefícios sociais à medida que os pais enlutados poderão ter a singularidade de seu processo de luto reconhecida. 


\section{Referências}

Almeida, T. C. S. (2017). A espiritualidade como elemento de resiliência psicológica no enfrentamento do luto: Uma análise a partir de estudos de casos de pais enlutados [Tese de Doutorado, Universidade Federal de Juiz de Fora]. Repositório Institucional UFJF. https://repositorio.ufff.br/jspui/handle/uff/4611

Andrade, M. L., Mishima-Gomes, F. K. T., \& Barbieri, V. (2017). Recriando a vida: o luto das mães e a experiência materna. Psicologia: teoria e prática, 19(1), 2132. https://dx.doi.org/10.5935/1980-6906/psicologia.v19n1p33-43

Bittencourt, A. L. P., Quintana, A. M., \& Campos Velho, M. T. A. (2011). A perda do filho: luto e doação de órgãos. Estudos de Psicologia, 28(4), 435442. https://dx.doi.org/10.1590/S0103-166X2011000400004

Bogensperger, J., \& Lueger-Schuster, B. (2014). Losing a child: finding meaning in bereavement. European Journal of Psychotraumatology, 5(1), 19. https://doi.org/10.3402/ejpt.v5.22910

Campos, E. B. V. (2013). Considerações sobre a morte e o luto na psicanálise. Revista de Psicologia da Unesp, 12(1), 1324.

Consonni, E. B., \& Petean, E. B. L. (2013). Perda e luto: vivências de mulheres que interromperam a gestação por malformação fetal letal. Ciência \& Saúde Coletiva, 18(9), 26632670. https://dx.doi.org/10.1590/ S1413-81232013000900021

Cremasco, M. V. F., Schinemann, D., \& Pimenta, S. O. (2015). Mães que perderam filhos: uma leitura psicanalítica do filme Rabbit Hole. Psicologia: ciência e profissão, 35(1), 5468. https://dx.doi.org/10.1590/1982-3703002152013

França, E. B., Lansky, S., Rego, M. A. S., Malta, D. C., França, J. S., Teixeira, R., Porto, D., Almeida, M. F., Souza, M. F. M., Szwarcwald, C. L., Mooney, M., Naghavi, M., \& Vasconcelos, A. M. N. (2017). Leading causes of child mortality in Brazil, in 1990 and 2015: Estimates from the Global Burden of Disease study. Revista brasileira de epidemiologia, 20(Supl. 1), 4660. https://dx.doi.org/10.1590/1980-5497201700050005

Franqueira, A. M. R., Magalhães, A. S., \& Féres-Carneiro, T. (2015). O luto pelo filho adulto sob a ótica das mães. Estudos de Psicologia, 32(3), 487497. https://dx.doi.org/10.1590/0103-166X2015000300013

Freitas, J. L. (2013). Luto e fenomenologia: uma proposta compreensiva. Revista da Abordagem Gestáltica, 19(1), 97105.

Freitas, J. L., \& Michel, L. H. F. (2014). A maior dor do mundo: o luto materno em uma perspectiva fenomenológica. Psicologia em Estudo, 19(2), 273283. https://dx.doi.org/10.1590/1413-737222324010

Freud, S. (1929). Lettre à Binswanger. In S. Freud, Correspondance: 1873-1939. Gallimard.

Freud, S. (2006). Luto e melancolia. In S. Freud, Edição standard das obras completas de Sigmund Freud (Vol. 14, pp. 99-122). Imago. (Trabalho original publicado em 1917)

Freud, S. (2006). Sobre o narcisismo: uma introdução. In S. Freud, Edição standard brasileira das obras psicológicas completas de Sigmund Freud (Vol. 14, pp. 95-122). Imago. (Trabalho original publicado em 1914)

Furtado, M. A. (2014). O lugar do sofrimento na cultura contemporânea: Patologização do mal-estar e medicalização da vida [Tese de Doutorado, Universidade Federal do Rio de Janeiro]. Programa EICOS. http://pos.eicos. psicologia.ufrj.br/wp-content/uploads/2014_DOUT_Mariama_Augusto_Furtado.pdf

Garcia-Roza, L. A. (2011). Introdução à metapsicologia freudiana 3. Jorge Zahar.

Gil, A. C. (2002). Como elaborar projetos de pesquisa (4a ed.). Atlas.

Kovács, M. J. (2003). Educação para morte: temas e reflexões. Casa do Psicólogo.

Lei n. 8.069, de 13 de julho de 1990. (1990, 16 de julho). Dispõe sobre o Estatuto da Criança e do Adolescente e dá outras providências. Diário Oficial da União. http://www.planalto.gov.br/ccivil_03/leis/18069.htm

Lemos, L. F. S., \& Cunha, A. C. B. (2015). Concepções sobre morte e luto: experiência feminina sobre a perda gestacional. Psicologia: ciência e profissão, 35(4), 11201138. https://dx.doi.org/10.1590/1982-3703001582014

Luna, I. J. (2014). Histórias de perdas: uma proposta de (re) leitura da experiência de luto [Tese de Doutorado, Universidade Federal de Santa Catarina]. Repositório Institucional UFSC. https://repositorio.ufsc.br/ handle/123456789/129248

Menezes, C. N. B., Passareli, P. M., Drude, F. S., Santos, M. A., \& Valle, E. R. M. (2007). Câncer infantil: organização familiar e doença. Revista Mal-Estar e Subjetividade, 7(1), 191210.

Minayo, M. C. S. (2014). O desafio do conhecimento: Pesquisa qualitativa em saúde (14a ed.). Hucitec. 
Monti, M. R. (2008). Contrato narcisista e clínica do vazio. Revista Latinoamericana de Psicopatologia Fundamental, 11(2), 239253. https://doi.org/10.1590/S1415-47142008000200006

Morelli, A. B., Scorsolini-Comin, F, \& Santos, M. A. (2013). Impacto da morte do filho sobre a conjugalidade dos pais. Ciência \& Saúde Coletiva, 18(9), 27112720. https://dx.doi.org/10.1590/S1413-81232013000900026

Parkes, C. M. (1998). Luto: estudos sobre a perda na vida adulta (M. H. Franco, Trad.). Summus.

Quintana, A. M., Wottrich, S. H., Camargo, V. P., Cherer, E. Q., \& Ries, P. K. (2011). Lutos e lutas: reestruturações familiares diante do câncer em uma criança/adolescente. Psicologia Argumento, 29(65), 143154.

Roitman, A., Armus, M., \& Swarc, M. (2002). El duelo por la muerte de un hijo. Aperturas psicoanalíticas: revista internacional de psicoanálisis, (12). http://www.aperturas.org/articulos.php?id=0000216

Santos, S. H., Oliveira, W., \& Jesus, C. F. (2015). Pais enlutados na sociedade atual: uma análise sobre suas vivências cotidianas a partir de novos critérios diagnósticos. Revista Ciências Humanas, 8(1), 98108. https://doi.org/ 10.32813/2179-1120.2015.v8.n1.a251

Turato, E. R. (2013). Tratado da metodologia da pesquisa clínico-qualitativa: Construção teórico-epistemológica discussão comparada e aplicação nas áreas da saúde e humanas. (6a ed.). Vozes.

Viorst, J. (2005). Perdas necessárias. Melhoramentos.

\section{Cristine Gabrielle da Costa dos Reis}

Doutora em Psicologia pela Universidade Federal de Santa Catarina (UFSC), Florianópolis - SC. Brasil.

E-mail: cristinecostareis@hotmail.com

(1) https://orcid.org/0000-0002-8935-4715

\section{Luísa da Rosa Olesiak}

Doutoranda em Psicologia pela Universidade Federal de Santa Maria (UFSM). Mestre em Psicologia pela UFSM), Santa Maria - RS. Brasil.

E-mail: luisa_drolesiak@hotmail.com

(1) https://orcid.org/0000-0002-2635-2675

\section{Mikaela Aline Bade München}

Psicóloga graduada pela UFSM. Residente do Programa de Residência em Intensivismo, Urgência e Emergência no Hospital Santa Cruz, Santa Cruz - SC. Brasil.

E-mail: mikaelaaline@hotmail.com

(1) https://orcid.org/0000-0001-7610-0030

\section{Alberto Manuel Quintana}

Doutor em Ciências Sociais pela Pontifícia Universidade Católica de São Paulo (PUC-SP). Professor titular na UFSM, Santa Maria - RS. Brasil.

E-mail: albertom.quintana@gmail.com

(1) https://orcid.org/0000-0001-7356-6142

\section{Camila Peixoto Farias}

Professora adjunta do curso de Psicologia da Universidade Federal de Pelotas (UFPEL). Coordenadora do Núcleo de Estudos e Pesquisas em Psicanálise (Pulsional), Pelotas - RS. Brasil.

E-mail: pfcamila@hotmail.com

(1) https://orcid.org/0000-0002-3442-5512

Apoio e agradecimento

Coordenação de Aperfeiçoamento de Pessoal de Nível Superior (Capes). 
Psicologia: Ciência e Profissão 2021 v. 41 (n.spe 3), e196821, 1-16.

Recebido 27/04/2018

Aceito 26/02/2019

Received 04/27/2018

Approved 02/26/2019

Recibido 27/04/2018

Aceptado 26/02/2019

Como citar: Reis, C. G. C., Olesiak, L. R., München, M. A. B., Quintana, A. M., \& Farias, C. P. (2021). O Luto de Pais: Considerações Sobre a Perda de um Filho Criança. Psicologia: Ciência e Profissão, 41 (n.spe 3), 1-16. https://doi.org/ $10.1590 / 1982-3703003196821$

How to cite: Reis, C. G. C., Olesiak, L. R., München, M. A. B., Quintana, A. M., \& Farias, C. P. (2021). Parents' Grief: Thoughts on the Loss of a Child. Psicologia: Ciência e Profissão, 41 (n.spe 3), 1-16. https://doi.org/10.1590/19823703003196821

Cómo citar: Reis, C. G. C., Olesiak, L. R., München, M. A. B., Quintana, A. M., \& Farias, C. P. (2021). El Duelo de los Padres: Consideraciones Sobre la Pérdida de un Hijo Todavía Niño. Psicologia: Ciência e Profissão, 41 (n.spe 3), 1-16. https://doi.org/10.1590/1982-3703003196821 